\title{
E-ENGINEERING: FROM CONCEPT TO REALITY
}

\author{
M. Gericota ${ }^{1}$, G. Andrieu' ${ }^{2}$, C. Dalmay ${ }^{2}$, M. Batarseh ${ }^{3}$, A. Fidalgo', P. Ferreira ${ }^{1}$ \\ ${ }^{1}$ Polytechnic of Porto, School of Engineering (PORTUGAL) \\ ${ }^{2}$ Université de Limoges (FRANCE) \\ ${ }^{3}$ Princess Sumaya University for Technology (JORDAN)
}

\begin{abstract}
Even before the digital era, the implementation of distance learning in higher education was a reality in many areas. Notwithstanding, the offer of distance higher education courses was not equal in all knowledge areas due to different teaching and learning requirements. The experimental work developed during the learning process in engineering areas is widely recognized as essential for engineering students. However, the remote availableness of this experimental, hands-on, works, typically done in University laboratories designed according to the different teaching subject requirements, was nonexistent.

With the advent of remote laboratories, real-time remotely controlled laboratory facilities made possible by the advancements on the Internet network, this limitation disappeared.

The concept of e-engineering, a merge between the e-learning concept and the remote laboratories, emerged as a solution to offer distance learning engineering courses without abdicating of the indispensable practical component of any engineering course.

Two European projects - the Tempus EOLES project and the ERASMUS+ e-LIVES project - try to bridge the gap between concept and reality by first implementing an accredited higher education engineering course in Electronics and Optics e-Learning for Embedded Systems and then by producing a set of guidelines to help others to be autonomous in the creation of their own eengineering courses.
\end{abstract}

Keywords: e-engineering, e-learning, remote laboratories, course accreditation.

\section{INTRODUCTION}

The number of worldwide students enrolled in tertiary education more than doubled since the end of the XX century, growing from 94.5 million in 1999 to almost 221 million in 2015, a gross enrolment ratio change from $19 \%$ to $36 \%$. However, these global figures hide major differences between regions. While in Europe and North America the higher education gross enrolment ratio is around $75 \%$, in the South and Eastern Mediterranean Basin countries the values range from $28 \%$ to $45 \%$ [1] [2].

In the last few years, however, higher education enrolment has been on the rise in this region. The graphic in figure 1 shows that the number of students enrolled in higher education in Morocco doubled in the last five years while in Algeria it incremented by a third in the same period. On the contrary, in Jordan and Tunisia, the number remained stable but rather below the desirable value, mainly when compared to the European rates [3]. Algeria is a successful case in this region. There, the percentage of students transitioning from upper secondary to tertiary education by the end of the school year 2015 was $109 \%$, meaning that a lot of students that had left school after the end of their secondary studies in the past are returning to continue their higher education studies [2].

This growth in the number of students in the tertiary education is highly encouraged by national governments committed to the development of higher education in advanced engineering fields physical sciences, computer sciences, engineering and engineering trades - perceived as essential to making their economies competitive in today's globalized knowledge society.

Despite being highly positive and desirable, the recent rise in the number of students in the higher education system in South and Eastern Mediterranean Basin countries created important challenges to Universities forced to handle overcrowded classes. These difficulties are particularly significant on some STEM (Science, Technology, Engineering, and Mathematics) related courses where the need for new laboratory spaces and associated equipment is critical. One promising solution involves the extensive development of nationally accredited e-learning undergraduate and graduate courses. This strategy prompted a group of Maghrebin High Education Institutions (HEIs) to join efforts with four 
European HEls under a European Tempus project named EOLES - Electronic and Optic e-Learning for Embedded Systems [4] -, whose motto was "engineering a brighter future anywhere", in the development of the first accredited e-engineering course, the L3-EOLES, an "e-Learning 2.0" Englishtaught 3rd year Bachelor degree course in Electronics and Optics for Embedded Systems.

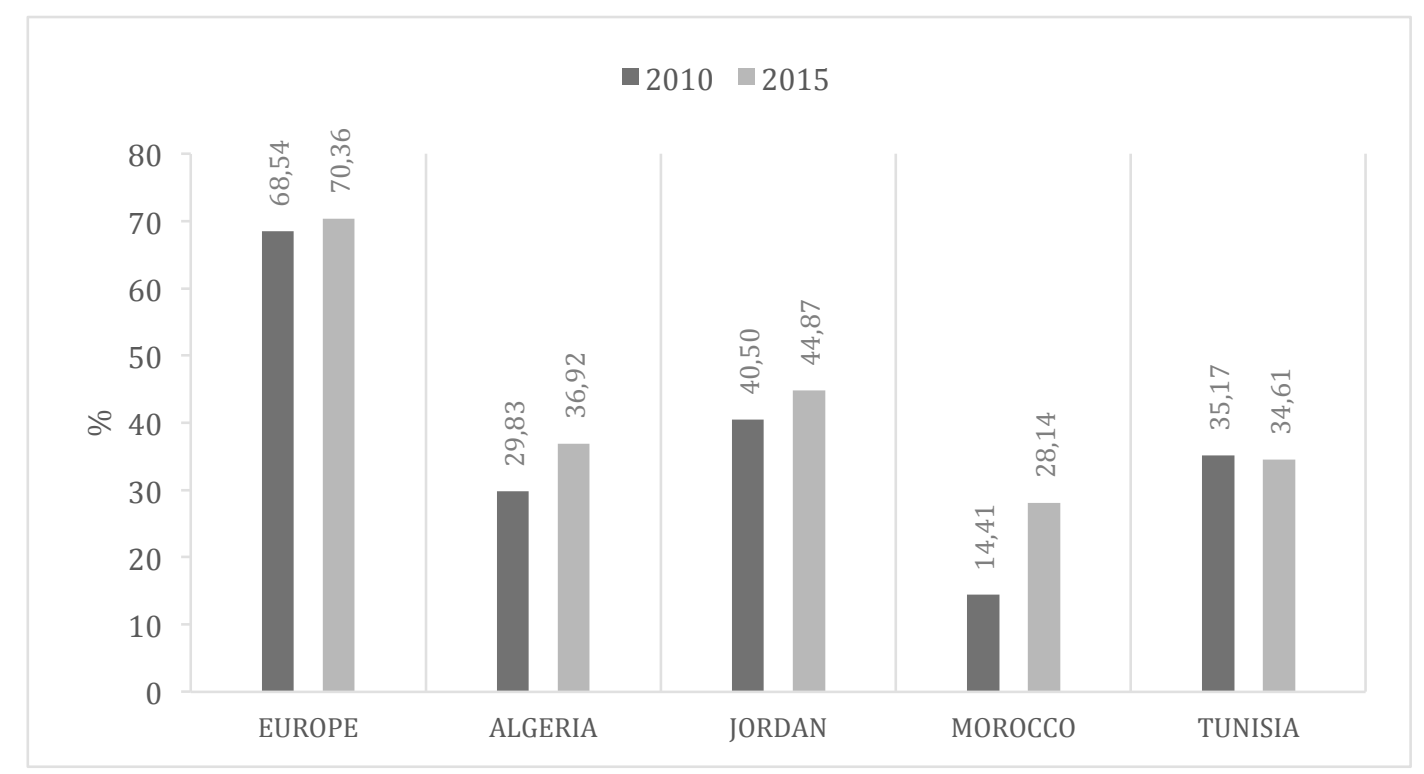

Figure 1. Gross enrolment ratio in tertiary education in the countries involved in the EOLES and e-LIVES projects [3]

The success of this first project and the interested it created in other Universities of the region prompted the determination of extending its results to other countries, in an effort of disseminating and consolidating the e-engineering concept. This determination led to the current ERASMUS+ e-LIVES (e-Learning InnoVative Engineering Solutions) project.

\section{THE E-ENGINEERING CONCEPT}

Notwithstanding the great revolution made possible by the development of data communication networks, especially the Internet, in the last 20 years, only during the last decade many established Universities started offering undergraduate e-learning courses, in addition to their classic on-site courses.

But while postgraduate level engineering courses awarding a final Certificate, Diploma or Master degree are easy to find (see, for example, the Master of Computer Science from the University of Illinois [5]), the undergraduate offer is mainly restricted to no-engineering areas. The widely available fully online Bachelor courses in Computer Science \& Information Technology [6] are the exception as the same computer students use to follow the courses are used to perform practical software development work in the field.

Rather generic Master degrees in engineering may also be found, but their content is essentially restricted to paper research work and writing. Apart from personal teaching guidance, no classes are generally provided. The only tools students have access are modeling and simulation tools. Indeed, they are the reason why Master degrees in Electrical and Computer Engineering are often found online.

Undergraduate courses in Electrical and Computer Engineering do exist, but either they require students to attend one- to two-week lab sessions on-campus usually during the summer months, or to do an internship or to possess some work experience in the area $[7,8]$. These conditions have obvious disadvantages. To attend on-campus face-to-face sessions students must have the necessary time and funds to travel. And additionally, the non-existence of synchronization among theoretical, tutorial and laboratory classes creates complications to the normal learning process by postponing the correct understanding and assimilation of the different subjects. On the other hand, the work experience of different students may differ substantially like the one obtained during different internships. The experience gained in a workplace albeit valuable tend to be focused on very specific aspects hindering 
the desired wider background knowledge an electrical engineer must possess. This wide background knowledge is essential for him/her to be able to successfully adapt him/herself to a technological world in constant change requiring continuous lifelong learning training.

This reality is changing with the advent of remote laboratories. These laboratories are real-time remotely controlled real physical laboratory facilities made possible by the developments on highspeed broadband networks, which enable students to remotely access and control in real-time a myriad of experiments in different areas of physics and electrical engineering [9].

The use of remote laboratories on a fully online engineering course enables the extension of the offer of distance learning courses to engineering courses without abdicating of the crucial practical component of any engineering course. This seems to be the natural path in the evolution of e-learning towards fully online accredited e-learning engineering courses enabling the transition of e-engineering from concept to reality.

\section{THE EOLES PROJECT}

The development of e-learning courses in tertiary education is one of the priorities of the educational strategy defined by the governments of Algeria, Morocco, and Tunisia, the partner countries involved in the first of the two European projects mentioned in this paper, the Tempus EOLES project Electronic and Optic e-Learning for Embedded Systems [4], which ran between October, 2012 and February, 2016. In Tunisia, the development and implementation of a national e-learning strategy was assigned to the Virtual University of Tunis (UVT) established in January 2002. The objective of UVT is to support the development of e-learning in the higher education system via partnerships with the Tunisian Universities. In Morocco, the government passed in 2014 a law authorizing the creation of elearning training (blended learning or fully online), while in Algeria, legislative texts governing distance education are being drafted.

The main objective of the EOLES project was the creation of the L3-EOLES (Electronics and Optics e-Learning for Embedded Systems) course, a fully on-line English-taught 3rd year Bachelor's degree in Electronics and Optics for Embedded Systems [10,11]. The project joined the expertise of the European partners - the University of Limoges, the Polytechnic of Porto - School of Engineering, KU Leuven and the Politehnica University of Bucharest - in such areas as e-learning 2.0 tools and simulation tools, and virtual and remote laboratories, with the intentions defined by the Maghrebin governments of developing higher education in advanced engineering fields. Eleven Universities from those countries participated in the project.

The three-year EOLES project gave partners the time and the resources to adequately prepare the first edition of the course while ensuring its continuity beyond project's end by agreeing on a suitable sustainability plan supported by the commitment of the Universities involved in the project, and by getting the accreditation of the course. Designed as a specialization year, the L3-EOLES course is oriented towards a currently expanding field in the electrical and computer engineering area, the embedded systems domain.

While Learning Management Systems (LMS) developed to support e-learning strategies, like the Moodle platform used to support the organization and delivery of the L3-EOLES course [12], are broadly available and can easily be installed in and maintained by the Universities that are delivering the course, this is not exactly the case with remote laboratories. It is possible to find many remote laboratories in different areas of physics and electrical engineering [9] readily available on the Internet, but to rely on them to support an accredited, fee-based, course like the L3-EOLES is not so straightforward. Laboratories must be available when necessary during the course and thus its maintenance and availability must be guaranteed. To assure this, the Universities that deliver the L3EOLES must have some form of control over these laboratories. Those who hold and make them freely available on the Internet neither receive any compensation nor have any obligation of keeping them operative. The only way to assure this is for participating Universities to create and install their own remote laboratory able to deliver in an integrated way with a common access interface all the laboratory works required all along the course.

Consequently, the Universities that integrated the consortium decided to create their own remote laboratory based on virtual experimentation, modeling and simulation platforms, and on remotely operated real instrumentation equipment installed in different Universities and used by students to acquire essential practical skills. 
The first edition of the course started in the middle of September 2014, within the project span to be possible to all project partners closely monitor its progress, identify any drawbacks, and immediately introduce any necessary adjustments and evaluate the results.

The course was recognized by the educational authorities of France, Morocco, and Tunisia. As a result, all successful students received a diploma recognized inside the European Higher Education Area (EHEA) and issued by the University of Limoges. Additionally, students from Morocco and Tunisia received a diploma issued by one of the accredited Universities of their home countries.

Four years after its first edition, the L3-EOLES continues to be a success. The course is now receiving students' applications for its 5th edition that will take place in the school year 2018/2019 [13].

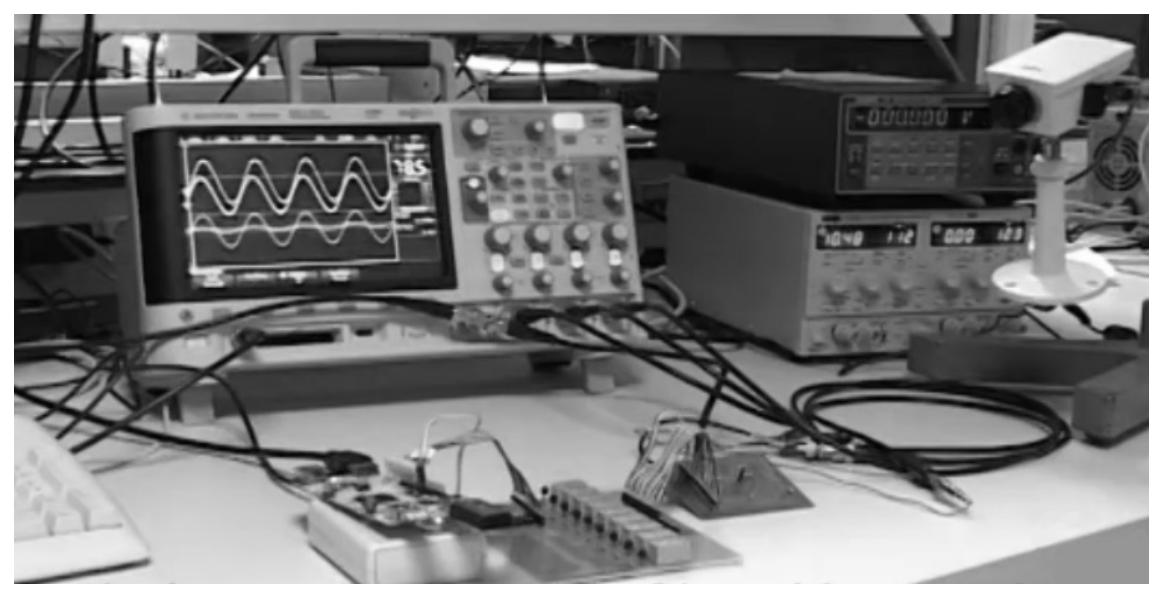

Figure 2. EOLES experimental remote laboratory setup.

As far as authors are aware, this is the first fully online accredited degree course in an area of engineering where the development of practical skills is fundamental, thanks to the innovative remote laboratory developed within the EOLES project. This is by far the most cutting-edge advancement in the field of e-learning, breaking new grounds in an area until now mostly dominated by blended learning.

\section{THE E-LIVES PROJECT}

The effectiveness of the use of virtual and remote laboratories in e-engineering courses was demonstrated by an extensive study published by James Brinson [14] and by our own experience after three L3-EOLES editions [15].

On the first edition of the L3-EOLES that took place in the school year 2014/2015, the number of applicants largely exceeded the initial expectations, with a total of 660 candidates, 633 from Morocco, fifteen from Tunisia, ten from Algeria, one from Senegal, and one from France. After a careful selection, 25 students were chosen. All of them were simultaneously enrolled at the University of Limoges and at one of the accredited Universities of their choice in their countries of origin. Of these 25 students, four abandoned the course due to personal reasons, and only eleven managed to successfully conclude it and receive the Joint Diploma, a success rate of only $44 \%$. Apart from those that abandoned the course, the remaining ten that did not succeed experienced mainly language problems, albeit having some previous English knowledge attested by their TOEFL (Test of English as a Foreign Language) certificates.

After a careful evaluation of the results and considering the feedback given by the students, some adjustments in the selection of students and on the organization of the course were made. These changes helped to improve the success rate in the following editions. In the second edition, 24 students, including two lifelong learning students, were selected from a number of applicants that surpassed the seven hundred. Lifelong learning students are part-time students allowed to complete the course in two years. These students were joined by eight repeaters. In this edition, the success rate improved to $70 \%-21$ graduates, including the eight repeaters, from 30 possible.

In the third edition, the number of applicants was almost eight hundred. 28 new students were selected, including one lifelong learning student. These students were joined by the seven repeaters 
and by one of the lifelong learning students enrolled on the second edition. The second one abandoned the course due to professional reasons. At the end of the school year, 24 students got their Diplomas, a success rate of around 66\% [15].

At the time of writing (May 2018), the success rate of the fourth edition is still unknown. Curious is the fact that for the first time the geographic origin of the students includes one from Canada and one from Spain, countries that were not part of the initial EOLES consortium, which demonstrates the interest and demand for this type of courses worldwide.

The success of the course attracted the attention of Universities in other countries also interested in the development of e-engineering courses. Nonetheless, if this previous EOLES project can be considered as a success story the impulse given is still insufficient to determine a fast growing on the creation and offer of e-engineering courses in the short term. This is the main shortcoming of the EOLES project that the e-LIVES project, a three-year ERASMUS+ European project that started in October 2017, tries to fill [16]. By documenting a set of good practices and following a hands-on approach, the aim of this latter project is to help partner countries' Universities to build innovative eengineering courses by themselves in a sustainable way.

Two objectives contribute to this goal:

- To create a detailed description of each one of the steps necessary to design and develop an e-engineering course - the building of a curriculum, the obtainment of the national accreditation, the training of teachers and technicians, the creation of the contents, the quality assessment ...;

- To create a detailed guideline that enables Universities to develop by themselves (from A to Z) a remote laboratory.

The long-lasting purpose of the e-LIVES project is to generate on partner countries - Algeria, Morocco, Tunisia, and Jordan -, a more committed and professional environment ready to introduce new forms of flexible learning into daily training activities and to create and manage accredited eengineering courses.

It is important to note that these remote laboratories can also be used in face-to-face training. Indeed, due to the exponential growth in students' number, numerous Universities had to replace the laboratory works in the first year of their Bachelor degrees in STEM fields by paper-and-pencil work. For this reason, this project is expected to have a direct structural impact on the higher education system modernization of the involved partner countries.

Apart from being an effective solution to cope with higher education access massification, e-learning in general and e-engineering in particular also meet multiple students' profiles. For instance, students with low economic resources living in distant isolated areas may pursue their higher education studies without leaving their homes and running into temporary expensive relocations. Furthermore, e-engineering courses provide lifelong learning students looking for professional development the flexibility they need to study after-hours and to progress at their own pace, pursuing their studies without interrupting their working careers.

\section{CONCLUSIONS}

By extending the concept of e-learning to the engineering field through the incorporation of remote laboratories in the e-learning flow, the EOLES project managed to successfully bridge the gap between the e-engineering concept and the reality of remote higher education engineering courses.

The e-EOLES successful story was realized by Universities in other developing countries also interested in the concept of e-engineering, prompting the proposal of the e-LIVES project whose main objective is making e-engineering courses mainstream, part of the general offer of engineering courses of Universities worldwide, by creating a set of documents, profiting from the consortium experience, that will detail all the steps Universities need to follow to create, develop, get accreditation and run in a sustainable way a successful e-engineering course.

\section{ACKNOWLEDGEMENTS}

These projects are funded by the European Commission under contract number 530466-TEMPUS-12012-1-FR-TEMPUS-JPCR, and under agreement number 2017 - 2891/001 -001. 
The European Commission support for the production of this publication does not constitute an endorsement of the contents which reflects the views only of the authors, and the Commission cannot be held responsible for any use which may be made of the information contained therein.

\section{REFERENCES}

[1] "Six ways to ensure higher education leaves no one behind", Policy Paper 30, Global Education Monitoring Report, United Nations Educational, Scientific and Cultural Organization (UNESCO), 2017

[2] "Accountability in education: Meeting our commitments", Global Education Monitoring Report Summary 2017/8, $2^{\text {nd }}$ edition, United Nations Educational, Scientific and Cultural Organization (UNESCO), 2017

[3] Data collected from the UNESCO Institute for statistics (2017), in Gross enrolment ratio by level of education. Accessed 16 November, 2017. Retrieved from http://uis.unesco.org/

[4] Electronic and Optic e-Learning for Embedded Systems - engineering a brighter future anywhere, EOLES, Accessed 8 May, 2018. Retrieved from http://www.eoles.eu/

[5] Master of Computer Science, The University of Illinois at Urbana-Champaign, Accessed 7 May, 2018. Retrieved from http://catalog.illinois.edu/graduate/graduate-majors/computerscience/master-sci-comp-sci/

[6] 50 Best Online Bachelor's in Computer Science \& IT Programs 2017, SuperScholar, Accessed 7 May, 2018. Retrieved from https://superscholar.org/rankings/best-online-bachelors-computerscience-it-programs/

[7] Bachelor of Engineering (Honours), The Open University, Accessed 7 May, 2018. Retrieved from http://www.openuniversity.edu/courses/qualifications/q65

[8] Best online Bachelor's in Electrical Engineering Programs, Best Colleges, Accessed 7 May, 2018. Retrieved from https://www.bestcolleges.com/features/top-online-electrical-engineeringprograms/

[9] Go Lab, Next-Lab - Next Generation Stakeholders and Next Level Ecosystem for Collaborative Science Education with Online Labs. Accessed 7 May, 2018. Retrieved from https://www.golabz.eu/

[10] Gericota M. et al, "EOLES course - The first accredited on-line degree course in Electronics and Optics for Embedded Systems," in Proc. IEEE Global Engineering Education Conference, 2015. EDUCON 2015. pp 410-417, 2015.

[11] Gericota M. et al, "Combining E-Technologies \& E-Pedagogies to Create Online Undergraduate Courses in Engineering - an Example of a Successful Experience," in Proc. 8th Intl. Conf. on Education and New Learning Technologies, 2016. EduLearn2016. pp 4209-4218, 2016.

[12] Moodle, Accessed 8 May, 2018. Retrieved from https://moodle.org/

[13] L3-EOLES - The university of future at home! Accessed 8 May, 2018. Retrieved from http:///3-eoles.unilim.fr/?lang=en

[14] J. R. Brinson, "Learning outcome achievement in non-traditional (virtual and remote) versus traditional (hands-on) laboratories: A review of the empirical research", Computers \& Education, vol. 87, pp. 218-237, 2015.

[15] G. Andrieu, D. Barataud, M. Gericota, "L3-EOLES - Electronics and Optics for Embedded Systems course," in The e-Learning Excellence Awards 2017: An Anthology of Case Histories (Dan Remenyi, ed.), pp. 22-35, Academic Conferences and Publishing International Limited, 2017.

[16] e-LIVES - Extending e-Engineering along the South and Eastern Mediterranean Basin, e-LIVES, Accessed 8 May, 2018. Retrieved from https://e-lives.eu/ 